\title{
Network Flow Optimization Model for Basin-Scale Water Supply Planning
}

\author{
Nien-Sheng $\mathrm{Hsu}^{1}$ and Ker-Wei Cheng ${ }^{2}$
}

\begin{abstract}
This paper develops a generalized network flow optimization model for long-term supply-demand analysis for basin-wide water resources planning. A set of nodes and arcs are used to form the network, and the decision variables are reservoir storage and water supply for public and agricultural uses. The objective function to be minimized is formed by summing the products of the decision variables multiplied by their corresponding cost coefficients. The constraints of the model include continuity equations, reservoir operation rule curves, reduced water supply due to water shortage, and evaporation losses from reservoirs. The formulated network model has losses in the transshipment and is solved by an efficient embedded generalized network solver (EMNET). The developed model is applied to a river basin located in the northern part of Taiwan. To analyze the characteristics of the model, the results obtained from the optimization model are compared with those obtained from a well-calibrated simulation model. The comparison shows that the water shortage computed by the optimization model is smaller than that computed by the simulation model. The developed model is then used to analyze future water supply-demand conditions for the area.
\end{abstract}

DOI: $10.1061 /(A S C E) 0733-9496(2002) 128: 2(102)$

CE Database keywords: Water resources management; Optimization models; Water supply; Networks; Reservoir storage.

\section{Introduction}

Traditionally, both simulation and optimization models are used for basin-wide water resources planning and management [see reviews by Yeh (1985) and Wurbs (1993)]. Simulation models analyze the results from various stipulated alternatives and then check for feasibility and optimality. It is inherently a trial-anderror approach and optimality is not assured. The major advantages of using a simulation model are that the model is easy to operate and it generally requires minimum computer time and storage. On the other hand, optimization models minimize or maximize a given objective function subject to the imposed set of constraints; thus the solution obtained is feasible and optimal. However, for large-scale water resources systems, this approach may become infeasible because of the dimensionality problem. In recent years, improvements in both computer capability and algorithm efficiency make the optimization models more attractive.

Originally, simulation models were common for water resources planning and management. Maass et al. (1962) used simulation to evaluate the benefit for basin-wide water resources planning. Hufschmidt and Fiering (1966) used simulation to study the planning problem of the Rhine River system under multiplereservoir and multiple-objective conditions. The U.S. Corps of Engineers developed HEC-5 (HEC 1979) for flood control and

\footnotetext{
${ }^{1}$ Associate Professor, Dept. of Civil Engineering, National Taiwan Univ., Taipei, Taiwan, ROC. E-mail: nsshue@ce.ntu.edu.tw

${ }^{2}$ Graduate Student, Dept. of Civil Engineering, National Taiwan Univ., Taipei, Taiwan, ROC.

Note. Discussion open until August 1, 2002. Separate discussions must be submitted for individual papers. To extend the closing date by one month, a written request must be filed with the ASCE Managing Editor. The manuscript for this paper was submitted for review and possible publication on November 1, 1999; approved on July 27, 2001. This paper is part of the Journal of Water Resources Planning and Management, Vol. 128, No. 2, March 1, 2002. CASCE, ISSN 0733-9496/2002/2$102-112 / \$ 8.00+\$ .50$ per page.
}

water conservation. Kuo and Young (1985) used stochastic simulation to derive joint operation policies for the Shimen and Feitui reservoirs. Delft Hydraulics (1991) developed a simulation model, RIBSIM, to analyze the long-term supply-demand planning in Taiwan. Chow (1995) formulated the simulation model into a network model for water resources management for the Tsenwen and Kaoping watersheds in southern Taiwan. Many researchers used linear programming to solve water resources planning and management problems. Loucks and Dorfman (1975) developed chance-constrained linear programming models to evaluate linear decision rules for reservoir planning and operation.

Certain types of the water resources planning and management problems formulated in terms of linear programming can also be formulated into network flow models. The most commonly used method to solve a pure network model, a network in which there is no gain or loss in the transshipment, is the out-of-kilter algorithm. These types of models include ACRES (Sigvaldason 1976), MODSIM3 (Labadie et al. 1986), WASP (Kuczera and Diment 1988), CRAM (Brendecke et al. 1989), DWRSIM (Chung et al. 1989), and KCOM (Andrews et al. 1992). Pure network models can also be solved by using the primal simplex algorithm (Kuczera 1989). Kuczera used decomposition along with the primal simplex algorithm to solve a generalized network model, although computational efficiency was sacrificed. McBride (1985) used the network simplex method along with matrix partition to develop EMNET, which can be used to solve an embedded generalized network model.

Sun et al. (1995) compared the efficiency of MINOS (Murtagh and Saunders 1987) and EMNET in analyzing the long-term supply-demand planning problem for the Metropolitan Water District of Southern California and concluded that the latter was 11 to 117 times faster than the former. Sun et al. (1996) demonstrated the use of EMNET to solve a water distribution system with losses. Yeh and Yang (1997) formulated the water resources man- 
agement problem in the Chianan area in Taiwan into a network model and solved it by EMNET.

The purpose of this paper is to formulate the long-term planning problem for a large-scale water resources system into a generalized network model. The formulation takes into account the reservoir operation rule-curves, reduced water supply due to water shortage, and evaporation losses from reservoirs. The developed model assumes that the statistics of the past flow process as recorded in the data will repeat in the future. The methodology is applied to two river basins within the greater Tanshui River basin, located in the northern part of Taiwan.

\section{Network Formulation of Basin-Wide System}

\section{Construction of Network Framework}

A basin-wide supply-demand system is usually constructed by combining various conveyance, storage, diversion, and pump facilities as well as the demand and supply points. Conveyance facilities include natural rivers, canals, and pressure conduits. Storage facilities include reservoirs and detention ponds. Demand points include cities, industrial areas, agricultural lands, and minimum requirements for environmental purposes. To proceed with the network formulation, nodes are introduced to represent reservoirs, diversions, public demand points, agricultural demand points, minimum requirement points, and source points. In addition, arcs are used to represent river reaches, pipelines, reservoir storage zones, and paths that link all water uses. Each arc is subject to an upper and lower bound. The framework of the network is then constructed by connecting the nodes and arcs according to their physical locations in the system.

\section{Network Formulation of Reservoir Operation Rule Curves}

Reservoir operation can be categorized into normal operation and flood-mitigation operation. During the normal operation period, rule-curves are usually used. For most reservoirs in Taiwan, three rule-curves are designated to separate the reservoir storage into four zones throughout the year, as shown in Fig. 1. The curves are called upper limit, lower limit, and extreme lower limit. The operational policy is then defined based upon the storage status at the beginning of each time period.

To incorporate the rule-curves and their associated operational policy into the network framework, four arcs are introduced to connect the two adjacent time periods $t$ and $t+1$ of the same reservoir node, as can be seen in Fig. 2. The $\operatorname{arcs} X_{R, 1, t}, X_{R, 2, t}$, $X_{R, 3, t}$, and $X_{R, 4, t}$ represent the four zones. Each arc has its own inflow and outflow multiplier, upper and lower bound, and unit cost coefficient. By properly assigning the values for the upper and lower bounds and the unit cost coefficients for the four arcs, the rule-curves and their associated operational policy can be completely described. As can be seen in Table 1, the upper bounds of the four arcs are $\Delta V_{1}, \Delta V_{2}, \Delta V_{3}$, and $\Delta V_{4}$, the lower bounds are all zero, and the unit cost coefficients are $\alpha_{1}, \alpha_{2}, \alpha_{3}$, and $\alpha_{4}$. Then, the four zones of the rule-curves can be described by the following equations:

$$
\begin{gathered}
\Delta V_{1}=V_{1}-V_{2} \\
\Delta V_{2}=V_{2}-V_{3} \\
\Delta V_{3}=V_{3}-V_{4} \\
\Delta V_{4}=V_{4}
\end{gathered}
$$

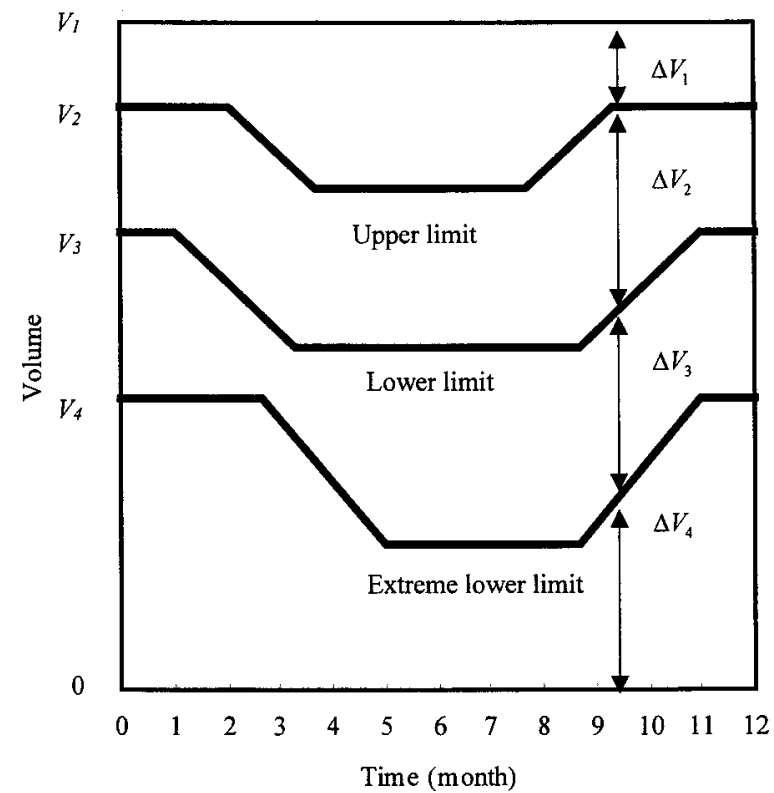

Fig. 1. General zonation of reservoir capacity

where $\Delta V_{1} \sim \Delta V_{4}=$ upper limit of zones 1, 2, 3, and 4; $V_{1}=$ reservoir capacity; $V_{2}=$ upper limit of the rule curves; $V_{3}=$ lower limit of the rule curves; and $V_{4}=$ extreme lower limit of the rule curves.

To conform to the fact that inflow into a reservoir is stored from the lowest (fourth) zone, first the unit cost coefficients of the four arcs $\alpha_{1} \sim \alpha_{4}$ need to follow the following relationship:

$$
\alpha_{4}<\alpha_{3}<\alpha_{2}<\alpha_{1}
$$

As can also be seen from Table 1, if no loss occurred in the reservoir storage arc $i$, then the inflow and outflow multipliers $\gamma_{i}$ and $\lambda_{i}$ of the arcs are -1 and 1 , respectively. The negative value denotes that water in the arc is flowing into a node, whereas the positive value denotes that water in the arc is flowing out of a node.

\section{Network Formulation of Hedging Rule}

When reservoir storage is below the extreme low limit during a drought period, the demand cannot be fully met and is usually subject to reduction. This rule is called hedging (Yeh and Yang 1997). The network formulation of the hedging rule is similar to that of the rule curves. As can be seen from Fig. 3, the demand from a demand point is separated into two zones by the reduced demand $D_{2}$. The volumes of the two zones are $\Delta D_{1}$ and $\Delta D_{2}$, respectively. The network framework of the hedging rule can be

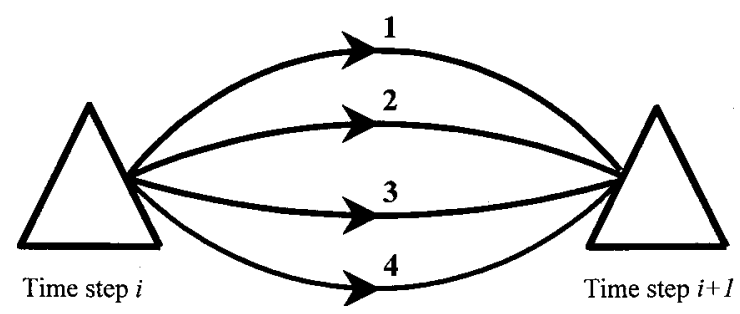

Fig. 2. Arcs connecting reservoir zones between consecutive timesteps 
Table 1. Parameters of Arcs Connecting Reservoir Zones between Consecutive Time-Steps

\begin{tabular}{lccccc}
\hline \multicolumn{5}{c}{ Parameters } \\
\cline { 2 - 6 } $\begin{array}{l}\text { Arc } \\
(i)\end{array}$ & $\begin{array}{c}\text { Inflow } \\
\text { Multiplier } \\
\left(\gamma_{i}\right)\end{array}$ & $\begin{array}{c}\text { Outflow } \\
\text { Multiplier } \\
\left(\lambda_{i}\right)\end{array}$ & $\begin{array}{c}\text { Lower } \\
\text { Bound }\end{array}$ & $\begin{array}{c}\text { Upper } \\
\text { Bound }\end{array}$ & $\begin{array}{c}\text { Unit } \\
\text { Cost }\end{array}$ \\
\hline 1 & -1 & 1 & 0 & $\Delta V_{1}$ & $\alpha_{1}$ \\
2 & -1 & 1 & 0 & $\Delta V_{2}$ & $\alpha_{2}$ \\
3 & -1 & 1 & 0 & $\Delta V_{3}$ & $\alpha_{3}$ \\
4 & -1 & 1 & 0 & $\Delta V_{4}$ & $\alpha_{4}$ \\
\hline
\end{tabular}

represented by Fig. 4. Two arcs, $X_{D, 1, t}$ and $X_{D, 2, t}$, are used to convey water from $\Delta D_{1}$ and $\Delta D_{2}$ to the demand point during time period $t$. As can be seen in Table 2, the upper bounds of the two arcs are $\Delta D_{1}$ and $\Delta D_{2}$, the lower bounds are all zero, and the unit cost coefficients are $\beta_{1}$ and $\beta_{2}$. Then the two zones of the hedging rule can be described by the following equations:

$$
\begin{gathered}
\Delta D_{1}=D_{1}-D_{2} \\
\Delta D_{2}=D_{2}
\end{gathered}
$$

where $\Delta D_{1}, \Delta D_{2}=$ volumes of the two zones that separate the total demand; $D_{1}=$ total demand; and $D_{2}=$ reduced demand.

Since the reduced demand $D_{2}$ has to be supplied and satisfied first, the cost coefficient of the arc $X_{D, 2, t}$ has to be less than that of $X_{D, 1, t}$, that is,

$$
\beta_{2}<\beta_{1}
$$

As can also be seen from Table 2, the inflow and outflow multipliers $\gamma_{i}$ and $\lambda_{i}$ are -1 and 1 , respectively, if no loss occurred in the arc $i$ connecting to a demand node.

To consider the rule-curves as well as the hedging rule, the unit cost coefficients of the arcs introduced in the formulation of the rule-curves and the hedging rule have to be reordered. Assuming that the supply to a demand point is reduced, if the storage in

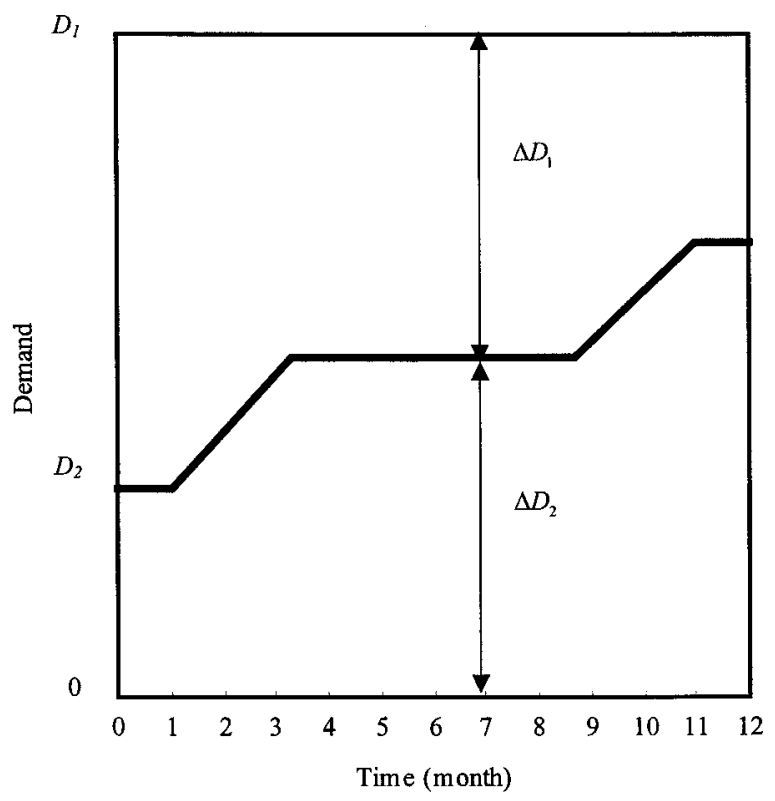

Fig. 3. General zonation of demand at demand node

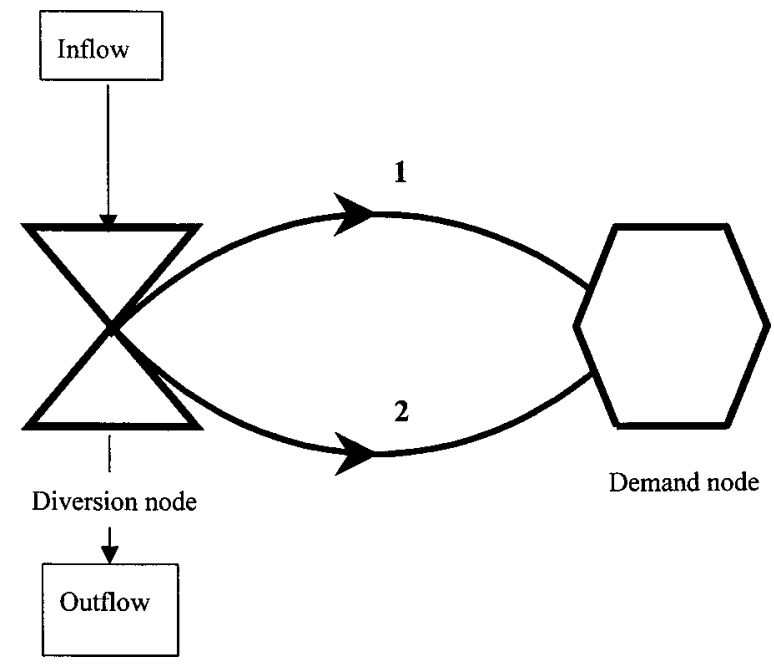

Fig. 4. Arcs connecting diversion node and demand node under reduced water supply conditions

the reservoir is below the extreme lower limit, the unit cost coefficients have to follow the following order:

$$
\beta_{2}<\alpha_{4}<\beta_{1}<\alpha_{3}<\alpha_{2}<\alpha_{1}
$$

\section{Network Formulation of Reservoir Evaporation Loss}

When evaporation loss in a reservoir is considered, the formulated network problem is no longer a pure-network problem but a generalized-network problem (Sun et al. 1996). To formulate the generalized-network problem, the outflow multiplier $\lambda_{i}$ will be in the range between 0 and 1 . In other words, if the loss rate is $l$, then $\lambda_{i}=1-l$.

Evaporation loss is usually proportionate to the surface area, which, in turn, is a nonlinear function of the reservoir storage. To maintain linearity of the formulation, the nonlinear function is piecewisely linearized. Assume that the four zones of the reservoir storage are adopted and the corresponding proportionality coefficients of surface area to storage are $m_{1}, m_{2}, m_{3}$, and $m_{4}$. Letting the corresponding surface area values of storage values $V_{1}, V_{2}, V_{3}$, and $V_{4}$ be $A_{1}, A_{2}, A_{3}$, and $A_{4}$, as well as allowing the corresponding surface area values of the upper bounds in the four zones be $\Delta A_{1}, \Delta A_{2}, \Delta A_{3}$, and $\Delta A_{4}$, one has $m_{i}$ $=\Delta A_{i} / \Delta V_{i}, i=1,2,3,4$.

If the evaporation rate $E_{t}$ (in depth) is known in a given time period $t$, then the ratio of evaporation to storage volume in each zone $i$ of the reservoir is $e_{R, i, t}=1-E_{t} m_{i}$. The outflow multipliers $\lambda_{1}, \lambda_{2}, \lambda_{3}$, and $\lambda_{4}$ of the four arcs connecting the reservoir node at period $t$ and period $t+1$ can easily be determined. Assume that the storage volume of the reservoir and its associated surface area

Table 2. Parameters of Arcs Connecting Diversion Node and Demand Node under Reduced Water Supply Conditions

\begin{tabular}{lccccc}
\hline \multicolumn{5}{c}{ Parameters } \\
\cline { 2 - 6 } & Inflow & Outflow \\
Arc & Multiplier & Multiplier & Lower & Upper & Unit \\
$\left(\gamma_{i}\right)$ & -1 & 1 & Bound & Bound & Cost \\
\hline 1 & -1 & 1 & 0 & $\Delta D_{1}$ & $\beta_{1}$ \\
2 & -1 & 0 & $\Delta D_{2}$ & $\beta_{2}$ \\
\hline
\end{tabular}


Table 3. Parameters of Arcs Connecting Reservoir Zones between Consecutive Time-Steps Subject to Evaporation Loss

\begin{tabular}{lccccc}
\hline \multicolumn{5}{c}{ Parameters } \\
\cline { 2 - 6 } $\begin{array}{c}\text { Arc } \\
(i)\end{array}$ & $\begin{array}{c}\text { Inflow } \\
\left(\gamma_{i}\right)\end{array}$ & $\begin{array}{c}\text { Outfliplier } \\
\text { Multiplier } \\
\left(\lambda_{i}\right)\end{array}$ & $\begin{array}{c}\text { Lower } \\
\text { Bound }\end{array}$ & $\begin{array}{c}\text { Upper } \\
\text { Bound }\end{array}$ & $\begin{array}{c}\text { Unit } \\
\text { Cost }\end{array}$ \\
\hline 1 & -1 & $1-E_{t} m_{1}$ & 0 & $\Delta V_{1}$ & $\alpha_{1}$ \\
2 & -1 & $1-E_{t} m_{2}$ & 0 & $\Delta V_{2}$ & $\alpha_{2}$ \\
3 & -1 & $1-E_{t} m_{3}$ & 0 & $\Delta V_{3}$ & $\alpha_{3}$ \\
4 & -1 & $1-E_{t} m_{4}$ & 0 & $\Delta V_{4}$ & $\alpha_{4}$ \\
\hline
\end{tabular}

at time period $t$ are $V_{t}$ and $A_{t}$ and assume that the storage volume is reduced to $V_{t}^{\prime}$ when the evaporation loss $E_{t} A_{t}$ is subtracted. Then one has

$$
V_{t}^{\prime}=V_{t}-E_{t} A_{t}
$$

By adopting the four zones of the reservoir storage and assuming that

$$
\begin{gathered}
V_{2} \leqslant V_{t} \leqslant V_{1} \\
V_{t}=V_{2}+\Delta V_{1 t} \\
A_{t}=A_{2}+\Delta A_{1 t}
\end{gathered}
$$

one has

$$
\begin{aligned}
V_{t}^{\prime}= & \left(\Delta V_{4}+\Delta V_{3}+\Delta V_{2}+\Delta V_{1 t}\right)-E_{t}\left(\Delta A_{4}+\Delta A_{3}+\Delta A_{2}+\Delta A_{1 t}\right) \\
= & \left(\Delta V_{4}-E_{t} \Delta A_{4}\right)+\left(\Delta V_{3}-E_{t} \Delta A_{3}\right)+\left(\Delta V_{2}-E_{t} \Delta A_{2}\right) \\
& +\left(\Delta V_{1 t}-E_{t} \Delta A_{1 t}\right) \\
= & \left(1-E_{t} m_{4}\right) \Delta V_{4}+\left(1-E_{t} m_{3}\right) \Delta V_{3}+\left(1-E_{t} m_{2}\right) \Delta V_{2} \\
& +\left(1-E_{t} m_{1}\right) \Delta V_{1 t} \\
= & \left(1-E_{t} m_{4}\right) X_{R, 4, t}+\left(1-E_{t} m_{3}\right) X_{R, 3, t} \\
& +\left(1-E_{t} m_{2}\right) X_{R, 2, t}+\left(1-E_{t} m_{1}\right) X_{R, 1, t} \\
= & \sum\left(1-e_{R, i, t}\right) X_{R, i, t}=\sum \lambda_{i} X_{R, i, t}
\end{aligned}
$$

Therefore, as can be seen from Table 3, the inflow multipliers $\gamma_{1}$, $\gamma_{2}, \gamma_{3}$, and $\gamma_{4}$ as well as the outflow multipliers $\lambda_{1}, \lambda_{2}, \lambda_{3}$, and $\lambda_{4}$ of the four arcs can be determined as follows:

$$
\begin{array}{ll}
\gamma_{1}=-1 ; & \lambda_{1}=1-E_{t} m_{1} \\
\gamma_{2}=-1 ; & \lambda_{2}=1-E_{t} m_{2} \\
\gamma_{3}=-1 ; & \lambda_{3}=1-E_{t} m_{3} \\
\gamma_{4}=-1 ; & \lambda_{4}=1-E_{t} m_{4}
\end{array}
$$

It is obvious that Eq. (6e) is valid for all four zones.

\section{Formulation of Network Model}

\section{Objective}

The standard form of the objective function of a network model is

$$
\operatorname{minimize} \sum_{(i, j) \in A} C_{(i, j)} X_{(i, j)}
$$

where $X_{(i, j)}=$ decision variable associated with arc $(i, j)$ that denotes flow rate leaving from node $i$ and entering into node $j$; $C_{(i, j)}=$ unit cost coefficient of $X_{(i, j)}$ associated with arc $(i, j)$; and $A=$ set of all arcs.

In this study, the objective function is to minimize the total cost of water transshipment; that is,

$$
\begin{aligned}
& \operatorname{minimize} \sum_{t}\left\{\sum_{R} \sum_{i} C_{R, i, t} X_{S, i, t}+\sum_{P} \sum_{i} C_{P, i, t} X_{P, i, t}\right. \\
& \left.+\sum_{F} \sum_{i} C_{F, i, t} X_{F, i, t}\right\}
\end{aligned}
$$

where $X_{R, i, t}=$ decision variable associated with a reservoir storage arc that denotes the ending storage in zone $i$ of reservoir node $R$ at time period $t ; X_{P, i, t}=$ decision variable associated with an arc $i$ that conveys public water supply to zone $i$ of demand node $P$ at time period $t ; X_{F, i, t}=$ decision variable associated with an arc $i$ that conveys agricultural water use to zone $i$ of demand node $F$ at time period $t ; C_{R, i, t}=$ unit cost coefficient associated with $X_{R, i, t}$; $C_{P, i, t}=$ unit cost coefficient associated with $X_{P, t, t}$; and $C_{F, i, t}=$ unit cost coefficient associated with $X_{F, t, t}$.

\section{Constraints}

The standard form of constraints in a network model is

$$
\sum_{(i, j) \in A} a_{(i, k)} X_{(i, k)}+\sum_{(k, i) \in A} a_{(k, i)} X_{(k, i)}=b_{k}
$$

where $X_{(i, k)}=$ decision variable associated with arc $(i, k)$ that denotes flow rate leaving node $i$ and entering node $k$; $X_{(k, j)}=$ decision variable associated with arc $(k, j)$ that denotes flow rate leaving node $k$ and entering node $j ; a_{(i, k)}=$ multiplier of $X_{(i, k)}$ in a constraint associated with node $k ; a_{(k, j)}=$ multiplier of $X_{(k, j)}$ in a constraint associated with node $k$; and $b_{k}=$ right-hand side of a constraint associated with node $k$.

It is obvious that the continuity requirement at each node poses a constraint. The formulation of the constraints associated with the six types of nodes considered in this paper is described below.

\section{Reservoir Nodes}

The constraints associated with a reservoir node $R$ account for continuity in both spatial and temporal domains. The rule curves and the hedging rule also must be satisfied. The constraints can be expressed as follows:

$$
-\sum X_{R, i, 1}+\sum X_{I, i, 1}-\sum X_{O, i, 1}=-\left(1-e_{R, 0}\right) S_{0}
$$

(for time period $t=1$ )

$$
\sum\left(1-e_{R, i, t}\right) X_{R, i, t-1}-\sum X_{R, i, t}+\sum X_{I, i, t}-\sum X_{O, i, t}=0
$$

(for time period $2 \leqslant t<T$ )

$$
\begin{gathered}
\sum\left(1-e_{R, i, t}\right) X_{R, i, T-1}+\sum X_{I, i, T}-\sum X_{O, i, T}=S_{0} \\
(\text { for time period } t=T) \\
0<X_{R, i, t} \leqslant \Delta V_{R, i, t}
\end{gathered}
$$

where $X_{R, i, t-1)}=$ decision variable associated with a reservoir storage arc that denotes the ending storage in zone $i$ of reservoir $R$ at time period $t-1 ; X_{R, i, t}=$ decision variable associated with a 
reservoir storage arc that denotes the ending storage in zone $i$ of reservoir $R$ at time period $t ; X_{I, i, t}=$ decision variable associated with an arc that denotes flow rate entering reservoir node $R$ at time period $t ; X_{O, i, t}=$ decision variable associated with an arc that denotes flow rate leaving reservoir node $R$ at time period $t$; $e_{R, i, t}=$ ratio of evaporation to storage in zone $i$ of reservoir $R$ at time $t ; S_{0}=$ initial storage of reservoir $R ; e_{R, 0}=$ ratio of evaporation to initial storage of reservoir $R ; T=$ total number of time periods; and $\Delta V_{R, i, t}=$ upper bound of $X_{R, i, t}$.

\section{Demand Nodes for Public Water Supply}

The constraint at a demand node $P$ for public water supply with a hedging rule is

$$
0<X_{P, i, t} \leqslant \Delta D_{P, i, t}
$$

where $X_{P, i, t}=$ decision variable associated with an arc that conveys public water supply to zone $i$ of demand node $P$ at time period $t$, and $\Delta D_{P, i, t}=$ upper bound of $X_{P, i, t}$.

\section{Demand Nodes for Agricultural Water Use}

The constraint at a demand node $F$ for agricultural water use with a hedging rule is

$$
0<X_{F, i, t} \leqslant \Delta D_{F, i, t}
$$

where $X_{F, i, t}=$ decision variable associated with an arc that conveys agricultural water use to zone $i$ of demand node $F$ at time period $t$, and $\Delta D_{F, i, t}=$ upper bound of $X_{F, i, t}$.

\section{Nodes for Water Diversion}

The constraints associated with a diversion node $D$ are

$$
\begin{gathered}
\sum X_{I, i, t}-\sum X_{O, i, t}-\sum X_{D, i, t}=0 \\
0<X_{D, i, t} \leqslant U_{D, i, t}
\end{gathered}
$$

where $X_{I, i, t}=$ decision variable associated with an arc that denotes flow rate entering node $D$ at time $t ; X_{O, i, t}=$ decision variable associated with an arc which denotes flow rate leaving node $D$ at time $t ; X_{D, i, t}=$ decision variable associated with an arc that denotes flow rate diverted from diversion node $D$ at time $t$; and $U_{D, i, t}=$ capacity limitation of diverted flow rate associated with $X_{D, i, t}$.

\section{Source Nodes}

The constraint associated with a source node $S$ is

$$
\sum X_{I, i, t}-\sum X_{O, i, t}=-\sum \mathrm{IN}_{S, i, t}
$$

where $X_{I, i, t}=$ decision variable associated with an arc that denotes flow rate entering the source node $S$ at time $t ; X_{O, i, t}=$ decision variable associated with an arc that denotes flow rate leaving source node $S$ at time $t$; and $\mathrm{IN}_{S, i, t}=$ flow rate from external source $i$ entering source node $S$ at time $t$.

\section{Junction Nodes}

The constraint associated with a junction node is

$$
\sum X_{I, i, t}-\sum X_{O, i, t}=0
$$

where $X_{I, i, t}=$ decision variable associated with an arc that denotes flow rate entering the junction node at time $t$, and $X_{O, i, t}=$ decision variable associated with an arc that denotes flow rate leaving the junction node at time $t$.
We now summarize the above-described formulation procedure for the proposed long-term, supply-demand analysis for $n$ years using a 10-day time period:

$$
\begin{aligned}
& \operatorname{minimize} \sum_{y=1}^{n} \sum_{t=36 \times(y-1)+1}^{36 \times y}\left\{\sum_{i \in A_{R}} C_{i, t} X_{i, t}+\sum_{i \in A_{P}} C_{i, t} X_{i, t}\right. \\
& \left.\quad+\sum_{i \in A_{F}} C_{i, t} X_{i, t}\right\}
\end{aligned}
$$

Subject to

$$
\begin{gathered}
\sum_{h_{i}=j}\left(1-e_{i, t-1}\right) X_{i, t-1}-\sum_{h_{i}=j} X_{i, t}+\sum_{g_{i}=j} X_{i, t}-\sum_{f_{i}=j} X_{i, t}=0 \\
j \in N_{R} \\
\sum_{g_{i}=j} X_{i, t}-\sum_{f_{i}=j} X_{i, t}=-\sum_{s_{i}=j} \mathrm{IN}_{i, t} \quad j \in N_{S} \\
\sum_{g_{i}=j} X_{i, t}-\sum_{f_{i}=j} X_{i, t}=0 \quad j \in N_{G} \\
0 \leqslant X_{i, t} \leqslant \Delta V_{i, t} \quad h_{i}=j \quad j \in N_{R} \\
0 \leqslant X_{i, t} \leqslant \Delta D_{j, t} \quad g_{i}=j \quad j \in N_{P} \\
0 \leqslant X_{i, t} \leqslant \Delta D_{j, t} \quad g_{i}=j \quad j \in N_{F} \\
0 \leqslant X_{i, t} \leqslant U_{i, t} \quad f_{i}=j \quad j \in N_{D} \\
t \in(36 \times(y-1)+1) \sim(36 \times y)
\end{gathered}
$$

where $n=$ number of years under planning; $y=$ yearly index; $t=$ time-step index; $e_{i, t-1}=$ ratio of evaporation to reservoir storage arc $i$ at time $t-1 ; X_{i, t}=$ decision variable associated with arc $i$ at time $t ; C_{i, t}=$ unit cost coefficient associated with $X_{i, t}$; $\mathrm{IN}_{i, t}=$ flow rate entering source node $s_{i}=j$ from external source $i$ at time $t ; \Delta V_{i, t}=$ upper bound of reservoir storage arc $i$ at time $t$; $\Delta D_{j, t}=$ upper bound of public-water-supply or agricultural-wateruse arc $i$ with head node $h_{i}=j ; U_{i, t}=$ capacity limitation of diverted flow rate in arc $i$ at time $t ; f_{i}=$ tail node of arc $i ; g_{i}=$ head node of arc $i ; h_{i}=$ reservoir node of storage arc $i ; s_{i}=$ source node which receives source $i ; A_{R}=$ set of all reservoir storage arcs; $A_{P}=$ set of all public-water-supply arcs; $A_{F}=$ set of all agricultural-water-use arcs; $N_{R}=$ set of all reservoir nodes; $N_{S}=$ set of all source nodes; $N_{G}=$ set of all junction nodes; $N_{P}=$ set of all demand nodes for public water supply; $N_{F}=$ set of all demand nodes for agricultural water use; and $N_{D}=$ set of all diversion nodes.

Note that Eq. (21) takes the following form for time-steps 1 and $T=36 \times y$ :

$$
\begin{gathered}
-\sum_{h_{i}=j} X_{i, 1}+\sum_{g_{i}=j} X_{i, 1}-\sum_{f_{i}=j} X_{i, 1}=\left(1-e_{j, 0}\right) S_{j, 0} \quad j \in N_{R} \\
\sum_{h_{i}=j}\left(1-e_{i, T-1}\right) X_{i, T-1}-\sum_{h_{i}=j} X_{i, T}+\sum_{g_{i}=j} X_{i, T}-\sum_{f_{i}=j} X_{i, T}=S_{j, 0} \\
j \in N_{R}
\end{gathered}
$$

where $S_{j, 0}=$ initial storage of reservoir $j$, and $e_{j, 0}=$ ratio of evaporation to initial storage of reservoir $j$.

\section{Model Application}

The developed model has been applied to a portion of the greater Tanshui River basin, located in the northern part of Taiwan (Fig. 


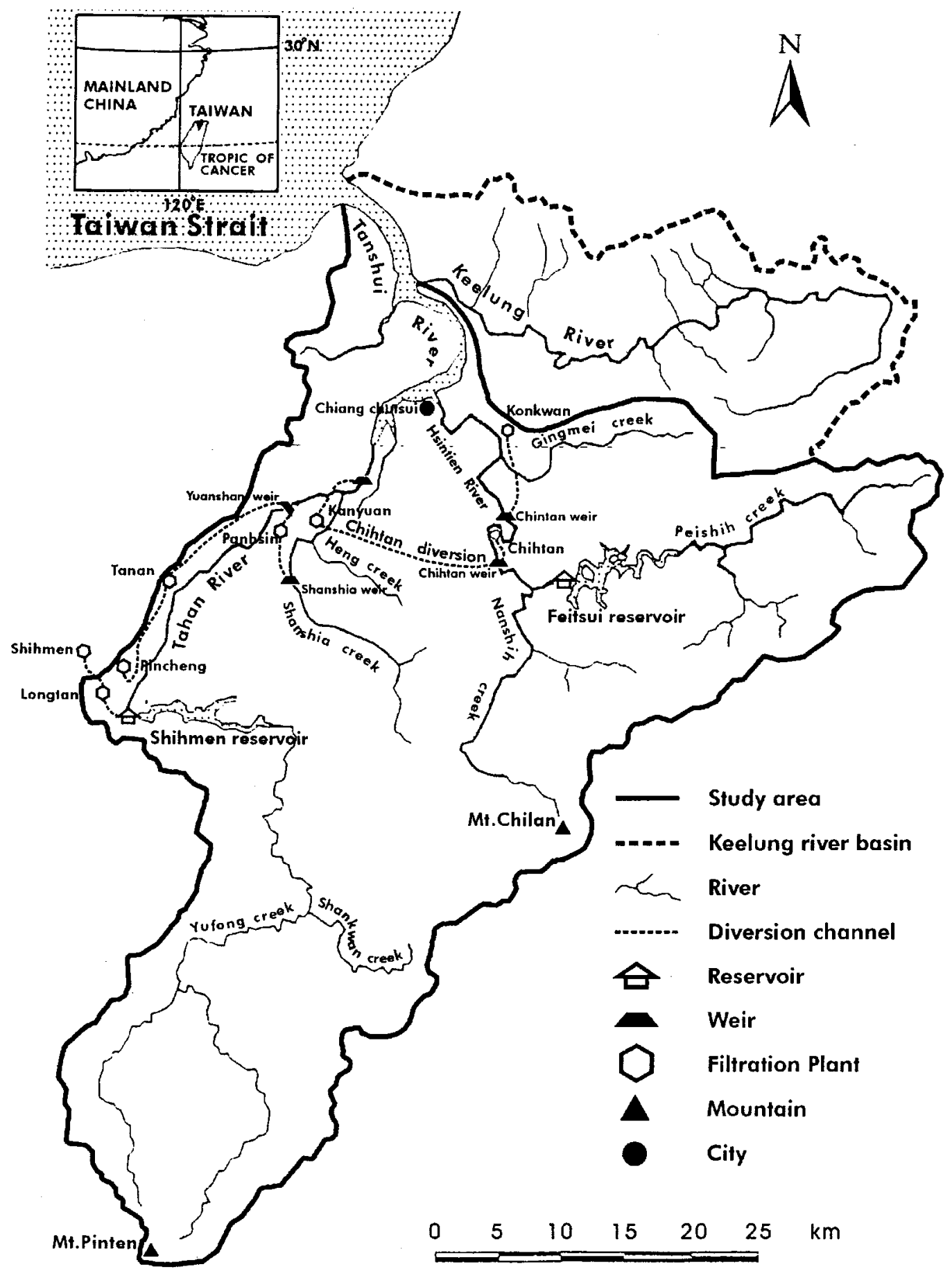

Fig. 5. Greater Tanshui River Basin

5). The greater basin consists of three major river basins: the Tahan River, Hsintien River, and Keelung River basins. Although the Tahan River and Hsintien River basins are hydrologically connected, the Keelung River basin is independent and hence not considered in the joint operation. Therefore, in the rest of this paper the term Tanshui River basin applies only to the Tahan River and Hsintien River basins.

\section{Tahan River Basin}

The Tahan River originates from Mt. Pinten and joins the Hsintien River at Chiang chutsui, which is the starting point of the
Tanshui River. The length of the Tahan River is $126 \mathrm{~km}$ with a drainage area of $1,163 \mathrm{~km}^{2}$. There are four major tributaries in the Tanhan River basin: Yufong creek, Shankwan creek, Shanshia creek, and Heng creek. The Shihmen reservoir, the most important hydraulic structure in the Tahan River basin, is located downstream of Yufong and Shankwan creeks and upstream of Shanshia and Heng creeks. The Shihmen reservoir, completed in 1964, has an effective storage capacity of $252 \times 10^{6} \mathrm{~m}^{3}$. Approximately 20 $\times 10^{6} \mathrm{~m}^{3}$ of the storage is reserved for flood control during the typhoon season (Hsu et al. 1995). The Shihmen reservoir was built primarily for irrigation and water supply along the Tahan River. The reservoir is currently managed by the Water Resources 
Department of the Ministry of Economic Affairs and has been operating according to the M-5 rule-curves, as depicted in Fig. 1. The capacity of the spillway and the spill-tunnel are $10,000 \mathrm{~cm} / \mathrm{s}$ and $2,400 \mathrm{~cm} / \mathrm{s}$, respectively. The capacity of the outlet is 34 $\mathrm{cm} / \mathrm{s}$. The M-5 rule-curves separate the reservoir capacity into four zones by the upper limit, the lower limit, and the extreme lower limit. The annual operational policy and its associated hedging rules can be found in WRPC (1994).

The Yuanshan weir, another major facility in the Tahan River basin, was built primarily for diversion of water to the Panhsin filtration plant. The capacity of the diversion is $11.57 \mathrm{~cm} / \mathrm{s}$.

\section{Hsintien River Basin}

The Hsintien River originates from Mt. Chilan and joins the Tahan River at Chiang chutsui. The length of the Hsintien River is $82 \mathrm{~km}$, with a drainage area of $916 \mathrm{~km}^{2}$. There are three major tributaries in the Hsintien River: Peishih creek, Nanshih creek, and Gingmei creek. The Feitsui reservoir, the most important hydraulic structure in the Hsintien River basin, is located on the Peishih creek. The Feitsui reservoir, completed in 1985, has an effective capacity of $327 \times 10^{6} \mathrm{~m}^{3}$ and was built primarily to provide domestic water supply to the Taipei Metropolitan area. The Feitsui reservoir is currently under the jurisdiction of the Taipei City government and has been operating according to its designed rule-curves. The capacity of the spillway, the spill-tunnel, and the spill sluiceway are $5,850 \mathrm{~cm} / \mathrm{s}, 1,500 \mathrm{~cm} / \mathrm{s}$, and $2,520 \mathrm{~cm} / \mathrm{s}$, respectively. The rule-curves separate the reservoir capacity into four zones by the upper limit, the lower limit, and the extreme lower limit. The annual operational policy and its associated hedging rules can be found in WRPC (1994).

The Chihtan weir and the Chintan weir are the other major facilities in the Hsintien River basin and are used for water diversion. The Chihtan weir is located downstream of the confluence of the Peishih and the Nanshih creeks. It is used to divert water to the Chihtan filtration plant. The diversion capacity is $31.25 \mathrm{~cm} / \mathrm{s}$. The Chintan weir is used to divert water to the Konkwan filtration plant. The diversion capacity is $12.56 \mathrm{~cm} / \mathrm{s}$.

\section{Water Use}

Public water supply and agricultural water use are the two major types of water use in the study area. The public water supply users include the districts of Taipei and Panhsin-Shihmen. Although Taipei users are supplied by the Feitsui reservoir, the Panhsin-Shihmen users are supplied by the Shihmen reservoir. The agricultural water users include Shihmen, Taoyuan, and the upper and lower Tahan River basins. All agricultural water users are supplied by the Shihmen reservoir.

Currently, the Hsintien system supports $15 \times 10^{4} \mathrm{~m}^{3} /$ day to the public water supply user of Panhsin. This support will be discontinued by 2008 and substituted by the supply from two major hydraulic facilities - namely, the Shanshia weir and the Chihtan transmountain diversion tunnel. The Shanshia weir will be completed by 2001 with a design capacity of $50 \times 10^{4} \mathrm{~m}^{3} /$ day, and the Chihtan transmountain diversion tunnel will be completed by 2008 with a design capacity of $100 \times 10^{4} \mathrm{~m}^{3} /$ day.

\section{Optimization Model for Study Area}

The network framework of the study area can be constructed based upon the above-mentioned information using 40 nodes and 68 arcs. The time period used in the model is 10 days, with a few
Table 4. Cost Coefficients Associated with Types of Arc Groups

\begin{tabular}{lc}
\hline Type of arc group & Cost coefficient \\
\hline Reservoir storage zone 1 & -10 \\
Reservoir storage zone 2 & -20 \\
Reservoir storage zone 3 & -38 \\
Reservoir storage zone 4 & -44 \\
Public water supply 1 & -42 \\
Public water supply 2 & -48 \\
Irrigation diversion 1 & -40 \\
Irrigation diversion 2 & -46 \\
\hline
\end{tabular}

exceptions at the end of some calendar months. Traditionally, a month is divided into three time periods. The first two time periods always contain 10 days, whereas the last time period varies from a minimum of eight days to a maximum of 11 days, depending upon the particular calendar month under consideration (Hsu 1995). In this paper, we will refer to the time period as the 10-day period, recognizing the fact that it may not be exactly 10 days. Let $T$ be the total number of time periods; then the total number of constraints is $(40 \times T)$.

\section{Input Data of Study Area}

The input data required to conduct the long-term supply-demand analysis for the study area are listed below.

\section{Inflows}

Twenty-three years of historical streamflows (1971-1993) have been collected at the Shihmen and Feitsui reservoirs and four stations located at Nanshih creek, Yufong creek, Shanshia creek, and Heng creek. The seven inflows to the six source nodes are then estimated by using the relationships suggested by the Water Resources Planning Commission of Taiwan (WRPC 1994).

\section{Demands}

Two demand nodes are used to represent the two public water supply users in the study area. The annual demands of the two users are estimated as $222.6 \times 10^{4} \mathrm{~m}^{3} /$ day and 128.6 $\times 10^{4} \mathrm{~m}^{3} /$ day, respectively, under the current conditions. The annual demands are also estimated as $240.5 \times 10^{4} \mathrm{~m}^{3} /$ day and $194.5 \times 10^{4} \mathrm{~m}^{3} /$ day, respectively, by 2011 (WRPC 1994).

Four demand nodes are used to represent the four agricultural water users in the study area. Due to the fact that a large portion of the agricultural land has been changed to industrial use, which has the highest priority of water right, it is assumed that agricultural water use will not increase in the future. The total annual demands of the four users are estimated as $132.0 \times 10^{4} \mathrm{~m}^{3} /$ day under the current conditions (WRPC 1994).

\section{Other Input Information}

Other required input information that can be found in WRPC (1994) includes the area-volume-elevation curves, the annual operation policies and monthly evaporation rates of reservoirs, the 10-day distribution of agricultural water use, and the 10-day distribution of public water supply use. The cost coefficients associated with the decision variables are categorized into eight types and are listed in Table 4.

\section{Numerical Results}

Three case studies are conducted to demonstrate model application. 


\section{Case Study 1}

The purpose of this case study is to indicate that, for planning purposes, the developed model, as expected, out-performs the RIBSIM model for not only minimizing the shortage but also following the operation and hedging rules. The RIBSIM model was jointly developed by Delft Hydraulics (1991) of the Netherlands and the Water Resources Planning Commission (WRPC) of Taiwan and has been well calibrated for the study area. Although the RIBSIM model does not strictly follow the rule-curves, there are two reasons for selecting the RIBSIM model for comparison purposes: (1) the RIBSIM model was originally developed for the study area and is well known in Taiwan; (2) the RIBSIM model gives reasonably good results (WRB 1999). The hydrologic data of 1993, a drought year, and the predicted demand of 2001, which is $1967.11 \times 10^{6} \mathrm{~m}^{3}$, are used. To ensure that the comparison is made on the same basis, a single-time-period optimization is used. In the single-time-period optimization, we formulate the network model for each 10-day period and solve it independently. The computed ending storage volumes of the Feitsui and Shihmen reservoirs in each time period serve as the initial storage volumes of the following time period. In other words, we are using optimization to solve the simulation problem in a manner that is consistent with the RIBSIM model. The total shortages computed by both models are $203.97 \times 10^{6} \mathrm{~m}^{3}$ and $139.04 \times 10^{6} \mathrm{~m}^{3}$, respectively. As can be expected, the developed model gives less water shortage.

\section{Case Study 2}

The purpose of this case study is to show that assigning the cost coefficients is crucial when applying the developed model to handle the rule-curves and the hedging rules. The results obtained from the developed model using both single-time-period and multiple-time-period optimization are also compared. The hydrologic data of 1978, a drought year, and the predicted demand of 2001 are used. The rule-curves of the Feitsui and Shihmen reservoirs along with their hedging rules are considered. In the case of multiple-time-period optimization, the initial storage volumes of the first time period and the ending storage volumes of the 36th period in the two reservoirs are identical to the ending storage volumes of 1977.

To consider the carry-over effect of storage, it was observed by Yeh and Yang (1997) that the unit cost coefficients associated with the storage arcs need to be modified. Supposing that a unit of flow is assigned to the arc at an early time period, a unit benefit (negative of cost), say $-\alpha_{4}$, will be introduced recursively at each time period before this unit of water is released from the reservoir. Therefore, the actual unit benefit for flow in a storage arc is larger than the original one. If a unit of flow in a supply arc is favorably compared to that in a storage arc, the unit benefit for the supply arc should be larger than that for the total benefit, including future benefit that the storage can bring to the system. At the beginning of the analysis the actual unit benefit for the flow in the first storage arc should be 36 times its original unit benefit for an analysis with 36 time periods. Therefore, to preserve the order of flow, fulfillment $\beta_{2}$ should be less than $36 \alpha_{4}$. Adopting the same concept, the unit cost coefficients should have values such that

$$
\beta_{2}<36 \alpha_{4}<\beta_{1}<36 \alpha_{3}<36 \alpha_{2}<36 \alpha_{1}
$$

In Eq. (29), $36 \alpha_{1}, 36 \alpha_{2}, 36 \alpha_{3}$, and $36 \alpha_{4}$ are used to account for the accumulative effects of the carry-over of storage during the thirty-six 10-day periods in one year.

The total shortages computed by both approaches are 41.74
Table 5. Sources and Filtration Plant Capacities for Public Water Supply under Current Conditions and in Years 2001 and 2011 $\left(10^{4} \mathrm{~cm} /\right.$ day $)$

\begin{tabular}{|c|c|c|c|c|c|c|}
\hline \multirow[b]{2}{*}{ Watershed } & \multicolumn{2}{|c|}{$\begin{array}{l}\text { Name of plant } \\
\text { and source }\end{array}$} & \multicolumn{2}{|c|}{$\begin{array}{l}\text { Current } \\
\text { conditions }\end{array}$} & \multicolumn{2}{|c|}{$\begin{array}{l}\text { Year } \\
2011\end{array}$} \\
\hline & $\begin{array}{l}\text { Filtration } \\
\text { Plant }\end{array}$ & Source & $\begin{array}{c}\text { Plant } \\
\text { Capacity }\end{array}$ & $\begin{array}{c}\text { Source } \\
\text { Capacity }\end{array}$ & $\begin{array}{c}\text { Plant } \\
\text { Capacity }\end{array}$ & $\begin{array}{c}\text { Source } \\
\text { Capacity }\end{array}$ \\
\hline \multirow[t]{2}{*}{$\begin{array}{l}\text { Hsintien } \\
\text { River }\end{array}$} & Chihtan & $\begin{array}{l}\text { Chihtan } \\
\text { weir }\end{array}$ & 165.0 & 270.0 & 270.0 & 270.0 \\
\hline & Konkwan & $\begin{array}{l}\text { Chintan } \\
\text { weir }\end{array}$ & 108.5 & 168.5 & 108.5 & 168.5 \\
\hline \multirow[t]{8}{*}{$\begin{array}{l}\text { Tahan } \\
\text { River }\end{array}$} & Longtan & $\begin{array}{l}\text { Shihmen } \\
\text { res. }\end{array}$ & 5.0 & 5.0 & 5.0 & 5.0 \\
\hline & Pincheng & $\begin{array}{l}\text { Shihmen } \\
\text { res. }\end{array}$ & 30.0 & 30.0 & 60.0 & 68.0 \\
\hline & Tanan & $\begin{array}{l}\text { Shihmen } \\
\text { res. }\end{array}$ & 30.0 & 25.0 & 50.0 & 25.0 \\
\hline & & $\begin{array}{c}\text { Yuanshan } \\
\text { weir }\end{array}$ & & 25.0 & & 25.0 \\
\hline & Shihmen & $\begin{array}{l}\text { Shihmen } \\
\text { res. }\end{array}$ & 12.0 & 12.0 & 12.0 & 12.0 \\
\hline & Panhsin & $\begin{array}{c}\text { Yuanshan } \\
\text { weir }\end{array}$ & 60.0 & 160.0 & 120.0 & 160.0 \\
\hline & & $\begin{array}{l}\text { Shanshia } \\
\text { weir }\end{array}$ & & - & & 50.0 \\
\hline & Kanyuan & $\begin{array}{l}\text { Chihtan } \\
\text { diversion }\end{array}$ & - & - & 100.0 & 100.0 \\
\hline
\end{tabular}

$\times 10^{6} \mathrm{~m}^{3}$ and 0 , respectively. As can be expected, the multipletime-period approach is more cost-effective and less conservative, due to the carry-over effect.

\section{Case Study 3}

The purpose of this case study is to show the efficiency of the developed model when it is applied to the Tanshui River basin-a real and large-scale system. The hydrologic data from 1971 to 1993 and the predicted demand with a moderate growth are used. The rule curves of the Feitsui and Shihmen reservoirs along with their hedging rules are considered. The initial storage volumes of the first time period in the two reservoirs are identical to the ending storage volumes of 1970 and the ending storage volumes of the $(36 \times 23)$ th period are set to be identical to the initial storage volumes of the first time period. To account for the effect of the carry-over of storage, cost coefficients are modified (Yeh and Yang 1997). The number of decision variables and constraints are 56,304 and 33,120, respectively. Each run of the optimization model takes about $11 \mathrm{~s}$ of CPU time on an HP9000/710 workstation.

Two alternatives that the governmental agency proposed (WRB 1999) are evaluated in this case study: current as well as projected conditions and planned construction of facilities for 2011. The major facilities under current conditions consist of Feitsui reservoir, Shihmen reservoir, Chihtan weir, Chihtan weir, and Yuanshan weir. Shanshia weir and Chihtan diversion are planned to activate by 2001 and 2008, respectively. Table 5 shows the sources and capacities of the filtration plants for public water supply under current conditions and target year 2011.

While Hsu (1995) proposed a generalized shortage index (GSI), the shortage index (SI) that was introduced by the U.S. Army Hydrologic Engineering Center (HEC 1966, 1975) is modi- 
Table 6. Results of Supply-Demand Analysis for Case Study 3

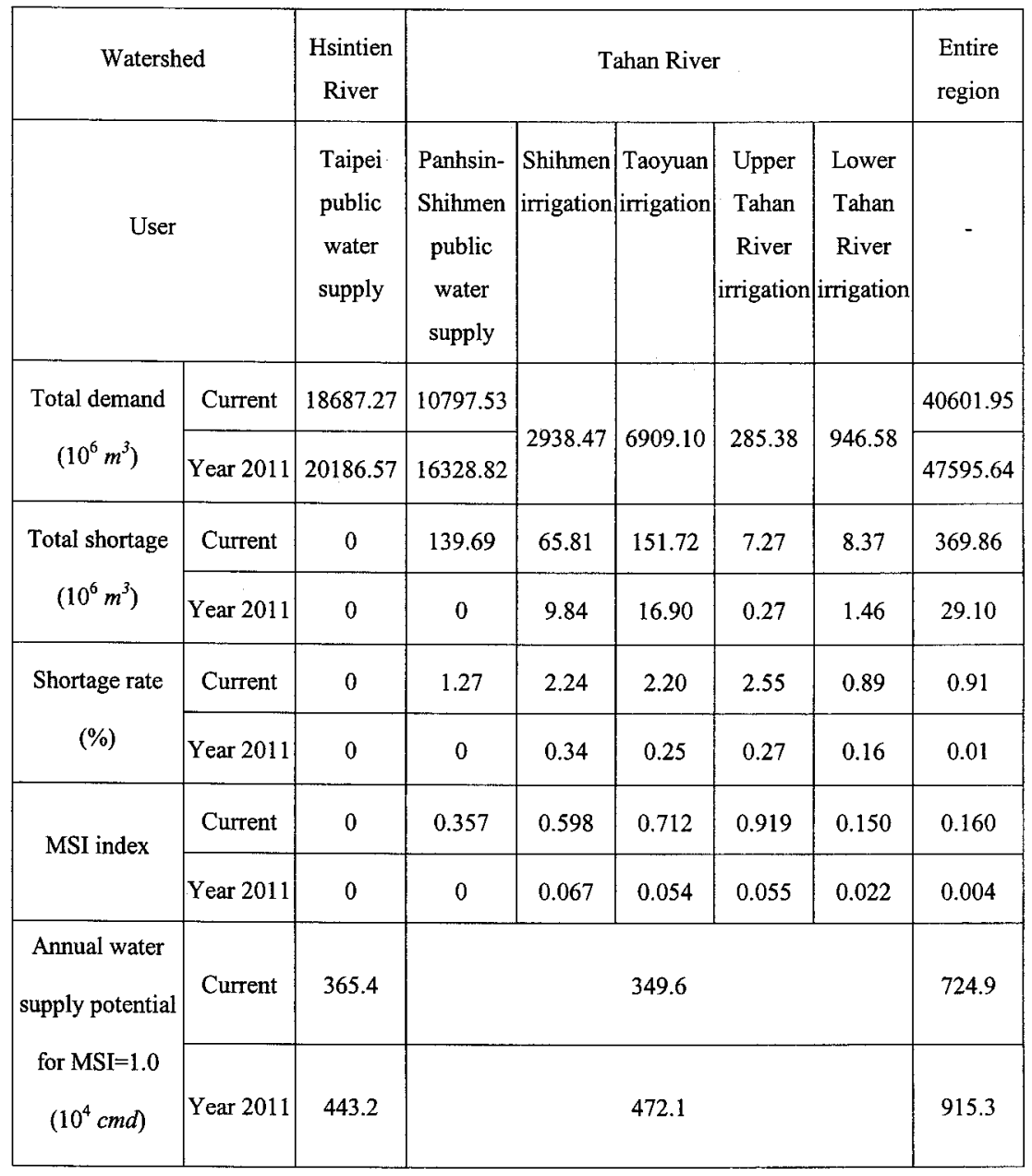

fied and used to indicate the degree of water shortage. The shortage index can be defined by the following:

$$
\mathrm{SI}=\frac{100}{n} \sum_{t=1}^{n}\left(\frac{\mathrm{AS}_{t}}{\mathrm{AD}_{t}}\right)^{2}
$$

where $\mathrm{SI}=$ shortage index; $\mathrm{AS}_{t}=$ annual shortage in $t$ th year; $\mathrm{AD}_{t}=$ annual demand in $t$ th year; and $n=$ number of years under planning.

This index has been used in the United States as an estimate of water shortage in connection with reservoir construction, and it also implies that the socioeconomic impact of deficit is proportional to the square of the deficit ratio. Moreover, because the SI index is the average of the annual deficit rate squared, the deficit frequency and intensity are incorporated in the index (Hsu 1995).

To characterize the extremely uneven distribution of the hydrologic conditions in Taiwan, a modified shortage index (MSI) is used and can be defined as the following:

$$
\mathrm{MSI}=\frac{100}{n^{\prime}} \sum_{t=1}^{n^{\prime}}\left(\frac{\mathrm{TS}_{t}}{\mathrm{TD}_{t}}\right)^{2}
$$

where $\mathrm{MSI}=$ modified shortage index; $\mathrm{TS}_{t}=$ shortage in $t$ th period; $\mathrm{TD}_{t}=$ demand in $t$ th period; and $n^{\prime}=$ number of 10 -day periods.

In this paper, a water deficit corresponding to $\mathrm{MSI}=1.0$ is considered to be tolerable and is used to determine the annual yield of the system, which is defined as the summation of the demand at all demand nodes under the condition that MSI $=1.0$. In reality, a trial-and-error approach needs to be carried out to obtain the annual yield, although we use the following algorithm to accelerate the search.

Step 1: Determine the upper bound of the yield by assuming that there is a reservoir with an unlimited capacity in the system and all the streamflow occurred during the simulation periods can be consumed.

Step 2: Determine the lower bound of the yield by assuming that there is no storage facility in the system and that there is no carry-over between the simulation periods.

Step 3: Determine the yield for a given system with known facilities by the following procedures:

1. Set the assigned demand equal to the average of the upper and lower bounds;

2. Compute the demand at all demand nodes;

3. Run the optimization model;

4. Compute the MSI index $M_{1}$

a. If $M_{1}$ is greater than 1.0 , set the upper bound equal to the assigned demand, then go to 5 ,

b. If $M_{1}$ is less than 1.0, set the lower bound equal to the assigned demand, then go to 5;

5. Repeat 1;

6. Repeat 2 and 3;

7. Compute the MSI index $M_{2}$

a. If $M_{2}$ is approximately equal to 1.0 , then go to 8 ,

b. Otherwise, carry out the linear interpolation using $M_{1}$ and 
$M_{2}$ and their associated demands to obtain the new assigned demand such that $\mathrm{MSI}=1.0$. Then assign $M_{2}$ to $M_{1}$ and go to 6; and

8. If converged, the assigned demand is the yield of the system.

The upper and lower bounds can easily be determined. For example, assume that the streamflows of the five periods are 3,5 , 12,2 , and 8 units. For a reservoir with an unlimited capacity, the demand without any shortage is 6 units. The upper bound can then be computed as 6.67 units (i.e., $100 / 5\left[5 \times(6-6.67 / 6.67)^{2}\right]$ $=1.0)$. If there is no storage, the lower bound can be computed as 2.58 units (i.e., $\left.100 / 5\left[0+0+0+(2-2.58 / 2.58)^{2}+0\right]=1.0\right)$. A spreadsheet is needed to compute the upper and lower bounds for a real problem, such as the given case study. Using the aboveoutlined algorithm, convergence takes place in at most five iterations.

The corresponding results obtained from the two alternatives are shown in Table 6. As can be seen from Table 6, the total demands under the current conditions for the Hsintien River system, the Tanhan River system, and the entire study area during the 23 years are $18,687.27 \times 10^{6} \mathrm{~m}^{3}, 21,914.68 \times 10^{6} \mathrm{~m}^{3}$, and $40,601.68 \times 10^{6} \mathrm{~m}^{3}$. The total shortages are $0,369.86 \times 10^{6} \mathrm{~m}^{3}$ and $369.86 \times 10^{6} \mathrm{~m}^{3}$. The MSI indices are 0 and 0.160 for the Hsintien River system and the entire study area. The annual water supply potentials for $\mathrm{MSI}=1.0$ are also computed as 365.4 $\times 10^{4} \mathrm{cmd}, 349.6 \times 10^{4} \mathrm{cmd}$, and $724.9 \times 10^{4} \mathrm{cmd}$ for the Hsintien River system, the Tanhan River system, and the entire study area. In other words, under the current conditions, the demand can be satisfied for MSI=1.0.

As can also be seen from Table 6, the total demands by 2011 for the Hsintien River system, the Tanhan River system, and the entire study area during the 23 years are $20,186.57 \times 10^{6} \mathrm{~m}^{3}$, $27409.07 \times 10^{6} \mathrm{~m}^{3}$, and $47595.64 \times 10^{6} \mathrm{~m}^{3}$. The total shortages are $0,0.01 \times 10^{6} \mathrm{~m}^{3}$ and $0.01 \times 10^{6} \mathrm{~m}^{3}$. The MSI indices are 0 and 0.23 for the Hsintien River system and the entire study area. The annual water supply potentials for $\mathrm{MSI}=1.0$ are also computed as $443.2 \times 10^{4} \mathrm{~m}^{3} /$ day, $472.1 \times 10^{4} \mathrm{~m}^{3} /$ day, and $915.3 \times 10^{4} \mathrm{~m}^{3} /$ day for the Hsintien River system, the Tanhan River system, and the entire study area. In other words, the demand can be satisfied for MSI $=1.0$ by 2011 if the construction of the Shanshia weir and the Chihtan diversion tunnel can be completed according to the planned schedule.

By comparing the annual water supply potentials for $\mathrm{MSI}=1.0$ in Table 6 , one can see that the annual water supply potentials are all largely increased for the Hsintien River system, the Tanhan River system, and the entire study area. For example, the annual water supply potential increases from $724.9 \times 10^{4} \mathrm{~m}^{3} /$ day under current conditions to $915.3 \times 10^{4} \mathrm{~m}^{3}$ /day by 2011 , while the MSI index decreases from 0.16 to 0.004 for the entire study area. This is because the capacities of the filtration plants are increased and the Chihtan diversion is tunnel expected to activate by 2011 .

\section{Conclusions}

A generalized network optimization model has been developed for basin-wide, long-term, supply-demand analysis. An efficient embedded generalized network solver (EMNENT) was used to solve the formulated model. The following contributions have been made in this paper: (1) Zoned reservoir operation rules coupled with the hedging rules have been incorporated and formulated in the model; (2) evaporation loss from a reservoir has been incorporated and formulated in the model; (3) an algorithm has been developed to efficiently determine the water supply po- tential; (4) the developed model has been applied to a real and large-scale problem for supply-demand analysis.

Several suggestions can be made for future study: (1) use the proposed network formulation to determine the optimal operation rules and the optimal design capacity of a reservoir; (2) modify the proposed network formulation to incorporate hydropower and typhoon release; (3) analyze the water supply potential of the greater Tanshui River basin, considering the construction of the proposed Pinglin reservoir located upstream of the Feitsui reservoir.

\section{References}

Andrews, E. S., Chung, F. I., and Lund, J. R. (1992). "Multi-layered, priority-based simulation of conjunctive facilities." J. Water Resour. Plan. Manage., 118(1), 32-53.

Brendecke, C. M., DeOreo, W. B., Payton, E. A., and Rozaklis, L. T. (1989). "Network models of water rights and system operations." $J$. Water Resour. Plan. Manage., 115(5), 684-696.

Chow, N. H. (1995). "A study on optimal management of water resources in Kaoping area, Taiwan (I)." Project Completion Rep. to National Science Council, Taipei, Taiwan, R.O.C. (in Chinese).

Chung, F. I., Archer, M. C., and DeVries, J. J. (1989). "Network flow algorithm applied to California aqueduct simulation." J. Water Resour. Plan. Manage., 115(2), 131-147.

Delft Hydraulics. (1991). "RIBSIM: River basin simulation." Project Completion Rep. to Water Resources Planning Commission, Taipei, Taiwan, R.O.C.

Hsu, S. K. (1995). "Shortage indices for water-resources planning in Taiwan.” J. Water Resour. Plan. Manage., 121(2), 119-131.

Hsu, N. S., Kuo, J. T., Chu, W. S., and Lin, Y. J. (1995). "Proposed daily streamflow-forecasting model for reservoir operation." J. Water Resour. Plan. Manage., 121(2), 132-143.

Hufschimidt, M. M., and Fiering, M. B. (1966). Simulation techniques for design of water resource system, Harvard University Press, Cambridge, Mass.

Hydrologic Engineering Center. (1966). "Reservoir yield, generalized computer program 23-J2-L245." U.S. Army Corps of Engineers, Davis, Calif.

Hydrologic Engineering Center. (1975). "Hydrologic engineering methods for water resources development: Vol. 8, reservoir yield." U.S. Army Corps of Engineers, Davis, Calif.

Hydrologic Engineering Center. (1979). "HEC-5, Simulation of flood control and conservation systems programming manual." U.S. Army Corps of Engineers, Davis, Calif.

Kuczera, G. (1989). "Fast multi-reservoir multi-period linear programming models." Water Resour. Res., 25(2), 169-176.

Kuczera, G., and Diment, G. (1988). "General water supply system simulation model: WASP.” J. Water Resour. Plan. Manage., 114(3), 365382.

Kuo, J. T., and Young, D. L. (1985). "Water resources system analysis in Tanshui River watershed." Project Completion Rep. to Water Resources Planning Commission, Taipei, Taiwan, R.O.C. (in Chinese).

Labadie, J. W., Bode, D. A., and Pineda, A. M. (1986). "Network model for decision-support in municipal raw water supply." Water Resour. Bull., 22(6), 927-940.

Loucks, D. P., and Dorfman, P. J. (1975). "An evaluation of some linear decision rule in chance-constrained models for reservoir planning and operation." Water Resour. Res., 11(6), 777-782.

Maass, A., Hufschmidt, M. M., Dorfman, R., Thomas, H. A., Jr., Marglin, S. A., and Fair, G. M. (1962). Design of water resource systems, Harvard University Press, Cambridge, Mass.

McBride, R. D. (1985). "Solving embedded generalized network problem." Eur. J. Oper. Res., 21, 82-92.

Murtagh, B. A., and Saunders, M. A. (1987). "MINOS 5.1 user's guide." Technical Rep. 50 L83-20R, Dept. of Operation Research, Stanford Univ., Stanford, Calif. 
Sigvaldason, O. T. (1976). "A simulation model for operating a multipurpose multi-reservoir system.” Water Resour. Res., 12(2), 263-278.

Sun, Y.-H., Yang, S., and Yeh, W. W-G. (1996). "Modeling reservoir evaporation losses by generalized networks." J. Water Resour. Plan. Manage., 122(3), 222-226.

Sun, Y-H., Yeh, W. W-G., Hsu, N. S., and Louie, P. W-F. (1995). "Generalized network algorithm for water-supply-system optimization." $J$. Water Resour. Plan. Manage., 121(5), 392-398.

Water Resources Planning Commission. (1994). "A study on optimal allocation of supply in Panhsin-Shihmen area." Project Completion Rep., Taipei, Taiwan, R.O.C. (in Chinese).
Water Resources Bureau. (1999). "Integrated water resources development plan in northern Taiwan." Project Completion Rep. Ji-Tin Consulting Engineering Co., Taipei, Taiwan, R.O.C. (in Chinese).

Wurbs, R. A. (1993). "Reservoir-system simulation and optimization models." J. Water Resour. Plan. Manage., 119(4), 455-472.

Yeh, W. W-G. (1985). "Reservoir management and operation models: A state-of-the-art review." Water Resour. Res., 21(12), 1797-1818.

Yeh, W. W-G., and Yang, S. (1997). "A study on the efficiency of water resources allocation." Project Completion Rep. to Water Resources Planning Commission, Taipei, Taiwan, R.O.C. 